\title{
Assessing the Patient Experience of Hypoparathyroidism Symptoms: Development of the Hypoparathyroidism Patient Experience Scale-Symptom (HPES-Symptom)
}

\author{
Meryl Brod ${ }^{1}$ (1) $\cdot$ Laura Tesler Waldman $^{1} \cdot$ Alden Smith $^{2} \cdot$ David Karpf $^{2}$
}

Published online: 25 September 2019

(c) The Author(s) 2019

\begin{abstract}
Background and Objective Hypoparathyroidism is a rare endocrine disorder characterized by absent or inappropriately low levels of circulating parathyroid hormone. Patients with hypoparathyroidism receiving standard-of-care therapy report debilitating physical and cognitive symptoms, which may indicate a reduced health-related quality of life. The purpose of this study was to develop a new disease-specific measure of the signs and symptoms of hypoparathyroidism, the Hypoparathyroidism Patient Experience Scale-Symptom (HPES-Symptom), and provide evidence for the content validity of items in the measure based on rigorous qualitative research methodologies for patient-reported outcome development.

Methods Semi-structured, individual concept elicitation interviews were conducted with five clinical experts and 42 adults with hypoparathyroidism in the USA to identify the signs and symptoms of relevance and importance to those with the condition. Transcripts were coded and analyzed using an adapted grounded theory approach. Following item generation, cognitive debriefing interviews of the draft measure were conducted in an independent sample of 16 adults with hypoparathyroidism. Results One hundred percent of the concept elicitation patient sample reported experiencing physical symptoms that were attributed to hypoparathyroidism, including tingling/numbness/paresthesia $(n=37,88 \%)$, muscle cramping $(n=36,86 \%)$, and physical fatigue $(n=35,83 \%)$. The majority of patients $(n=36,86 \%)$ further reported experiencing cognitive dysfunction, including impaired memory $(n=24,57 \%)$, impaired ability to have a conversation $(n=21,50 \%)$, and lack of concentration/ focus $(n=18,43 \%)$. Seventeen major signs and symptoms were identified during item generation and included in the preliminary measure. After the cognitive debriefing, the 17-item HPES-Symptom was generated.

Conclusions The findings provided evidence of content validity for the HPES-Symptom in US adults with hypoparathyroidism. Additional research is needed to validate the measure in patients with hypoparathyroidism to assess its psychometric properties.
\end{abstract}

\section{Background}

Hypoparathyroidism (HP) is a rare endocrine disorder characterized by absent or inappropriately low levels of circulating parathyroid hormone (PTH) [1, 2]. Parathyroid hormone is important in the homeostasis of calcium and phosphate in the body, the former within a narrow physiological range $[1,3]$. Parathyroid hormone is also a key hormone maintaining bone turnover [4-6]. Low levels or the absence of PTH circulating in the bloodstream can lead to hypocalcemia,

Meryl Brod

mbrod@thebrodgroup.net

1 The Brod Group, 219 Julia Avenue, Mill Valley, CA 94941, USA

2 Ascendis Pharma, 500 Emerson Street, Palo Alto, CA 94301, USA

\section{Key Points for Decision Makers}

Study findings suggest that patients with hypoparathyroidism experience a substantial burden of illness, both with respect to the range and severity of symptoms associated with the condition.

A validated disease-specific composite measure of symptoms in individual patients would be useful and help standardize the language used to describe the severity of the clinical syndrome in individual patients.

The validation-ready HPES-Symptom is intended to be a brief useful tool for assessing symptoms of hypoparathyroidism from the patient perspective, and for use in future studies that evaluate disease burden or treatment efficacy relating to symptom improvement among adults with hypoparathyroidism. 
hyperphosphatemia, hypercalciuria, and over-mineralized bone $[1,3]$.

The prevalence of HP in the USA is estimated to be between 70,000 and 115,000 patients [1,7-9], or up to 37 per 100,000 residents. A paucity of data exists on the global prevalence of this condition, but estimates available for other countries have been lower, ranging from approximately 25 per 100,000 residents in Denmark, to 10 per 100,000 residents in Norway, and 5.9 per 100,000 residents in Italy $[1,10]$. The most common source of HP is post-surgical, accounting for approximately $75 \%$ of cases [2,9]. It occurs when the parathyroid glands are irreversibly damaged or inadvertently removed, or their blood supply is damaged during anterior neck surgery $[2,9]$. The next most common etiology is auto-immune [2], characterized by the autoimmune destruction of the parathyroid glands leading to the loss of PTH secretion [11]. Idiopathic hypoparathyroidism occurs for unknown reasons [2]. Other etiologies include genetic mutations, severe and prolonged hypomagnesemia, hemochromatosis, Wilson disease, metastasis, and radiationinduced damage/fibrosis [1, 12-14].

Conventional treatment of HP, often referred to as standard of care (SoC), includes oral calcium and vitamin D supplements, often in large doses, with the goal of normalizing serum calcium levels [1-3, 14]. Parathyroid hormone [1-84] replacement therapy has also been approved by the US Food and Drug Administration for the treatment of HP in adults who cannot be well controlled with SoC $[1,15]$.

Hypoparathyroidism is associated with significant physical and cognitive symptoms [1]. Prior studies have found that patients with HP more frequently report experiencing symptoms such as fatigue, muscle spasms, paresthesia, and cognitive dysfunction, compared with either the general population $[16,17]$ or matched case controls $[18,19]$. In a web-based survey of 374 adult patients with HP, over half reported experiencing the following symptoms over the previous 12 months despite taking medications: fatigue, muscle pain/cramping, paresthesia, tetany, joint or bone pain, heaviness or weakness in the extremities, "brain fog", inability to focus or concentrate, forgetfulness, sleep disturbances, anxiety, and feeling sad or depressed [20]. More severe symptoms of HP include laryngospasm (spasm of the voice box), bronchospasm (spasm of the muscles that line the airways), cardiac arrhythmias, and seizures [1,2]. Additionally, there may be complications associated with the long-term use of calcium and vitamin D supplements, including premature cataracts, pseudotumor cerebri, soft-tissue calcifications, kidney stones, renal failure, and Parkinson's disease resulting from basal ganglia calcifications [1, 2, 9, 14].

Research indicates that patients with HP receiving SoC and/or PTH replacement therapy may have a reduced healthrelated quality of life (HRQOL) [1, 17, 21-23]. While several studies have used validated questionnaires to explore this, these questionnaires were not disease specific, and did not assess a number of symptoms associated with this condition, including cognitive deficits, fatigue, or decreased muscle strength [21, 24]. Moreover, because most patients with post-surgical HP also have post-surgical hypothyroidism, limited data are available on the extent to which reduced HRQOL is due to HP or the combination of HP and hypothyroidism [18]. Thus, there is a need to better understand, from the patient's perspective, the signs and symptoms experienced with HP.

The purpose of this study was to develop a new diseasespecific measure of the signs and symptoms of HP, the Hypoparathyroidism Patient Experience Scale-Symptom (HPES-Symptom), and provide evidence for the content validity of items in the measure based on rigorous qualitative research methodologies for patient-reported outcome (PRO) development. In addition, the study aimed to develop a preliminary theoretical model to identify relationships between signs and symptoms and their impacts on HRQOL related to the new PRO measure and inform future studies using the measure. Compared with generic measures, conditionspecific instruments should have greater face validity, be more responsive to change over time, and be more useful to both clinicians and researchers to assess the impact of treatment on patients with HP.

\section{Methods}

The HPES-Symptom was developed in accordance with the Food and Drug Administration guidance [25] and best research practices for PRO measure development [26-29]. Concept elicitation (CE) interviews with clinical experts and people with HP were used to inform the structure and content of the measure and to develop the preliminary theoretical model. Cognitive interviews were then conducted to ensure that instructions and items were clear, relevant, and inoffensive, and that the recall period and response options and scales were appropriate.

\subsection{Concept Elicitation}

Individual CE interviews were conducted by telephone with clinical experts and people with HP to identify key concepts of relevance and importance to the target population to inform the development of the PRO measure [28]. The key concepts of interest were the signs and symptoms of HP. Clinical experts and patient participants were also asked about how these signs and symptoms affected HRQOL (to be reported in a separate publication). The current literature on HP was used to inform the development of the semistructured interview guides, which included open-ended questions and probes. The patient participant interview 
guide was further developed based on input from the clinical expert interviews, and included questions asking not only what types of signs, symptoms, and impacts they experienced, but how bothersome these were and how frequently they were experienced.

Clinical expert interviews were conducted with physicians in the USA and Denmark who were recruited through a key opinion leader. Eligible clinical experts were wellestablished physicians currently practicing endocrinology and providing care to adult patients with HP.

Patient participants with HP were recruited via a national hypoparathyroidism organization and required to verify their eligibility by answering screening questions over the telephone and providing documentation of their diagnosis. Because of the low prevalence of people with HP, it was necessary to recruit participants throughout the USA, which in turn required that participants be interviewed by telephone because travel to each participant's location was unfeasible. However, studies have shown telephone interviews [30-32] to be a valid qualitative research method and a rich source of data.

Eligible participants needed to be at least 18 years old; be able to read, write, and speak English; have a diagnosis of HP of either at least 6 months (post-surgical), or at least 12 months (auto-immune or idiopathic); and be stable on SoC (oral calcium and vitamin D supplements) and/or shortacting PTH replacement therapy for at least 3 months. Stable was defined as experiencing infrequent severe hypo- or hypercalcemia requiring infusion treatment no more than one or two times in the past 3 months. Exclusion criteria were having HP due to a CASR mutation or pseudohypoparathyroidism; another condition that may affect calcium or phosphate metabolism; impaired renal dysfunction, defined as having Chronic Kidney Disease Stage 4 or 5 (estimated glomerular filtration rate $\leq 30 \mathrm{~mL} / \mathrm{min} / 1.73 \mathrm{~m}^{2}$ ); or a cognitive impairment or other medical condition, including psychiatric disorders, that would impact an individual's ability to participate in a telephone interview.

The individual interviews with clinical experts and patient participants were completed by trained qualitative research interviewers familiar with HP. Interviews lasted approximately $1 \mathrm{~h}$ and were conducted in an open-ended conversational style, generally following the semi-structured interview guides, but also responding to participants' thoughts. Thus, while the interviews were not identical, each followed the general themes and scope of the guides. Completed interviews were also used to guide and inform subsequent interviews as emergent issues that were raised by experts and patient participants in earlier interviews were further explored. Interviews were audio-recorded and transcribed verbatim. Clinical expert and patient participant names were replaced with unique ID numbers in the transcripts prior to analysis.
The study was approved by the Copernicus Group Institutional Review Board (tracking \#420180290). Informed consent was obtained from all patient interview participants.

\subsection{Qualitative Data Analysis}

Data were qualitatively analyzed through an adapted grounded theory approach, entailing developing and refining a theory based on concepts derived during the research process [33]. This involved iteratively analyzing the participant and clinical expert interview transcripts for content by theme using Dedoose (http://www.dedoo se.com), a qualitative analysis software program. For the portion of the study related to the development of the HPES-Symptoms measure, the overarching theme was the signs and symptoms associated with HP, and the key concepts within these were the specific signs and symptoms that patient participants reported experiencing and/ or clinicians reported observing in their patients. Following the completion of the interviews, a preliminary code list of themes and concepts was created based on the interview guides. Next, each transcript was read once, initially coded, and then reviewed multiple times. Within each study population (patient and physician), transcripts were coded in chronological order by when the interviews were conducted. Throughout the coding process, emerging concepts (signs and symptoms) were added to the coding scheme as they arose, and earlier transcripts were re-evaluated for the new concepts. Concepts were also iteratively reviewed to assess whether any redundancies among them existed, or whether any concept categories appeared to encompass multiple discrete concepts that needed to be separated from one another. Finally, the coded concepts were organized into larger categories of major themes (the signs and symptoms domains) for each study population, refining the preliminary themes based on the analysis and internal deliberations and consensus among the research team. Thematic saturation, defined as that point in time when no new major themes or concepts emerged, [34] was evaluated through the development of a saturation grid populated with the key concepts that were discussed in each participant interview.

To address the question raised in the literature about the extent to which impaired HRQOL may be due to HP as a stand-alone condition vs. HP combined with hypothyroidism, comparative frequencies for the overall endorsement rates (the percentage of participants who spontaneously reported or affirmed in response to interview probing) of physical and cognitive symptoms were examined based on the proportions of participants with vs. without hypothyroidism. Differences of at least $20 \%$ in the proportions of participant endorsement rates between these subgroups were considered to be potentially meaningful. Given that the 
meaningful difference was not explored in the interviews, the $20 \%$ threshold cannot be considered a clinically meaningful difference.

\subsection{Item Generation}

A 3-day, in-person, item generation meeting was held by the project research team. In accordance with Food and Drug Administration guidelines and good practices for PRO measure development, the team established criteria to identify signs and symptoms of importance and relevance to patients, including patients with differing demographic characteristics and disease severity levels [25-29]. Minimum percentages were included for CE participant endorsement of items, with some exceptions, to ensure the relevance of items to the target population and to avoid floor effects in the measure. The final agreed-upon criteria for the consideration of signs and symptoms as major included:

1. Endorsement by at least $30 \%$ of patient participants (including both participants who spontaneously reported experiencing a particular sign or symptom and those who affirmed experiencing it in response to interview probing), or by $20-29 \%$ if warranted by additional justification (e.g., if considered to be extremely bothersome by participants who reported these signs and symptoms);

2. For concepts that appeared to include overlapping but potentially multiple distinct issues, such as muscle spasms vs. muscle twitching, each issue would be provisionally categorized as major, even if the endorsement rates fell below $20 \%$, pending results of the cognitive debriefing (CD) interviews; items found to be distinct conceptually and endorsed as both relevant and bothersome by a majority of $\mathrm{CD}$ participants would be retained as major concepts;

3. Must be clearly linked to the burden of illness rather than the burden of treatment;

4. Considered as bothersome to participants; and

5. Must be proximal. Proximal symptoms were considered more immediate (e.g., muscle cramping), while distal symptoms were considered longer term (e.g., poorer overall health).

All issues not fulfilling these criteria were categorized as minor, distal, or a modifier. The criteria for categorizing concepts as minor included:

1. Endorsement of at least $10 \%$ but less than $20 \%$ of participants; and

2. Endorsement of $20-29 \%$ of participants with no additional justification for inclusion as a major issue.
Based on decisions regarding major and minor symptoms, a theoretical model was developed for the relationships among the key concepts of interest and to identify potential modifying factors [26]. Based on the qualitative analysis, the major signs and symptoms identified, and the preliminary theoretical model, the team then generated the preliminary measure items and created an item definition table, which specified each item's intent and acceptable synonyms, using the language of the participants as closely as possible for each item.

\subsection{Cognitive Debriefing Interviews}

Following item generation, $\mathrm{CD}$ interviews were conducted to reach a consensus on the appropriate format and structure of the measure; ensure that items, response options, and instructions were clear and relevant; confirm that the recall period was reasonable; and ensure that the content was comprehensive [26, 29]. The interviews were conducted in an independent sample of patients with HP who met the same eligibility criteria as the CE sample. Participants were emailed the HPES-Symptom in advance and asked to complete it $24-48 \mathrm{~h}$ prior to their interview, and to have it with them for the interview.

A semi-structured interview guide with relevant probes was used to direct the cognitive interview process. Interview questions focused primarily on participants' comprehension and perceptions of each item and the instructions, and also addressed issues of formatting, wording, content, recall period, response options, and relevance, using verbal probing techniques as needed. Individual interviews were conducted in blocks of four respondents each and edits were made in between blocks based on participants' comments. This process continued until a determination was made that the readability and relevance were acceptable based on a consensus agreement among the participants in the final block. Once the final block of cognitive interviews was completed, a validation-ready version of the measure was produced, and the preliminary theoretical model was updated to incorporate findings from the cognitive interviews.

\section{Results}

\subsection{Concept Elicitation}

\subsubsection{Sample Description}

A total of five expert interviews were conducted with wellestablished metabolic bone disease-specialist endocrinologists whose practices were located in the USA $(n=3,60 \%)$ and in Denmark $(n=2,40 \%)$. On average, the physicians had been treating patients with HP for 16 (range 5-30) years. 
Physicians reported seeing an average of 12 (range 1-40) patients with HP of all ages per month and having an average of 60 (range 2-140) adult patients with HP in their practice. Three physicians worked in academic medical centers $(60 \%)$ and two worked at university hospitals (40\%).

A total of 43 adults participated in the telephone interviews; however, one participant was excluded from the data analysis because her childhood polio had an impact on her physical and daily life functioning. Thus, 42 participants were included in the data analysis. The majority were female $(n=35,83 \%)$, and the average age was 53 (range 26-76) years. The majority $(n=36, n=86 \%)$ identified the source of their HP as post-surgical while $14 \%(n=6)$ reported the source as idiopathic. On average, participants had HP for 14 (range 1-49) years. Participants reported having an average of five (median 4, range 0-20) comorbidities in addition to their HP, including hypothyroidism $(n=30,71 \%)$, osteoarthritis $(n=16,38 \%)$, and depression $(n=12,29 \%)$. Nearly all participants reported currently using vitamin D ( $n=41,98 \%)$ or calcium supplements $(n=40,95 \%)$, and more than half reported currently using magnesium supplements $(n=24,57 \%)$ or PTH replacement therapy $(n=22$, $52 \%$ ) to manage their HP. Table 1 presents the demographics and health characteristics of the study participants.

\subsubsection{Qualitative Analysis}

Thematic and conceptual saturation was assessed for the 42 participant interviews in the order in which they occurred. A total of 67 concepts (including all signs and symptoms that were reported by at least one participant) of HP emerged from the interviews. After the 17th interview, $75 \%$ of signs and symptoms had been discussed, and by the 39th interview, $95 \%$ were covered.

Participants and clinical experts reported a total of 51 physical signs and symptoms, as shown in Table 2 . The most frequently reported signs and symptoms included tingling/numbness/paresthesia $(n=37,88 \%)$, muscle cramping $(n=36,86 \%)$, physical fatigue $(n=35,83 \%)$, pain $(n=32,74 \%)$, sleep issues $(n=21,50 \%)$, muscle spasms/twitching ( $n=20,48 \%)$, muscle weakness/fatigue/ decreased stamina $(n=17,40 \%)$, heat intolerance $(n=14$, $33 \%)$, and cardiovascular symptoms $(n=14,33 \%)$.

Participants and clinicians reported a total of $13 \mathrm{cog}$ nitive signs and symptoms, as shown in Table 3 . The most frequently reported cognitive signs and symptoms included memory impairment/forgetfulness $(n=24,57 \%)$, conversation/speech issues $(n=21,50 \%)$, lack of concentration/focus $(n=18,43 \%)$, unable to think clearly/“fuzzy thinking" ( $n=13,31 \%)$, and impaired ability to understand information $(n=11,26 \%)$. The vast majority of participants who reported experiencing cognitive symptoms $(32 / 36,89 \%)$ also used the term "brain fog" or affirmed experiencing "brain fog" when queried about it during the interviews. Based on the analysis, it appears that participants used this phrase as a catch-all umbrella term to

Table 1 Concept elicitation participant demographic and health characteristics

\begin{tabular}{|c|c|}
\hline Demographic and health characteristics & Total $(n=42)$ \\
\hline \multicolumn{2}{|l|}{ Sex, $n(\%)$} \\
\hline Female & $35(83)$ \\
\hline Male & $7(17)$ \\
\hline \multicolumn{2}{|l|}{ Age, years } \\
\hline Mean & 53 \\
\hline Median & 56 \\
\hline Range & $26-76$ \\
\hline \multicolumn{2}{|l|}{ Race/ethnicity, $n(\%)$} \\
\hline White/Caucasian & $40(95)$ \\
\hline Other & $2(5)$ \\
\hline \multicolumn{2}{|l|}{ Household income, $n(\%)$} \\
\hline Less than US $\$ 25,000$ & $3(7)$ \\
\hline US $\$ 25,000-U S \$ 49,999$ & $7(17)$ \\
\hline US\$50,000-US\$74,999 & $4(10)$ \\
\hline US\$75,000-US\$99,999 & $9(21)$ \\
\hline US\$100,000-US\$149,999 & $6(14)$ \\
\hline More than US $\$ 150,000$ & $2(5)$ \\
\hline Decline to answer & $11(26)$ \\
\hline \multicolumn{2}{|l|}{ Source of hypoparathyroidism, $n(\%)$} \\
\hline Post-surgical & $36(86)$ \\
\hline Idiopathic & $6(14)$ \\
\hline \multicolumn{2}{|l|}{ Duration of diagnosis, years } \\
\hline Mean & 14 \\
\hline Median & 9 \\
\hline Range & $1-49$ \\
\hline \multicolumn{2}{|l|}{ Self-reported other medical conditions, $n(\%)$} \\
\hline Hypothyroidism & $30(71)$ \\
\hline Osteoarthritis & $16(38)$ \\
\hline Depression & $12(29)$ \\
\hline Chronic back pain & $10(24)$ \\
\hline Reflux disease & $9(21)$ \\
\hline Thyroid cancer & $8(19)$ \\
\hline \multicolumn{2}{|c|}{$\begin{array}{l}\text { Medications and supplements currently used to treat hypoparathy- } \\
\text { roidism, } n(\%)^{\mathrm{a}}\end{array}$} \\
\hline Calcium supplements & $40(95)$ \\
\hline Vitamin D supplements & $41(98)$ \\
\hline PTH replacement therapy (PTH [1-84]) & $22(52)$ \\
\hline Hydrochlorothiazide & $7(17)$ \\
\hline Magnesium supplements & $24(57)$ \\
\hline Potassium supplements & $7(17)$ \\
\hline
\end{tabular}

Percentages may not add to 100 because of rounding PTH parathyroid hormone

${ }^{\text {a}}$ Participants could choose more than one response for the medications and supplements that they currently take 
Table 2 Patient- and clinicianreported physical signs and symptoms $^{\mathrm{a}}$

\begin{tabular}{|c|c|c|c|c|}
\hline \multirow[t]{2}{*}{ Physical signs and symptoms, $n(\%)$} & \multicolumn{2}{|c|}{ Comorbidity status } & \multirow{2}{*}{$\begin{array}{l}\text { Patient total } \\
(n=42)\end{array}$} & \multirow{2}{*}{$\begin{array}{l}\text { Clinician } \\
\text { total }(n=5)\end{array}$} \\
\hline & $\begin{array}{l}\text { Has hypothy- } \\
\text { roidism }(n=31)\end{array}$ & $\begin{array}{l}\text { Does not have hypo- } \\
\text { thyroidism }(n=11)\end{array}$ & & \\
\hline Tingling/numbness/paresthesia & $27(87)$ & $10(91)$ & $37(88)$ & $4(80)$ \\
\hline Tingling without numbness & $15(48)$ & $5(45)$ & $20(48)$ & $1(20)$ \\
\hline Tingling with numbness & $11(35)$ & $4(36)$ & $15(36)$ & $3(60)$ \\
\hline Unspecified & $1(3)$ & $1(9)$ & $2(5)$ & $0(0)$ \\
\hline Muscle cramping & $26(84)$ & $10(91)$ & $36(86)$ & $3(60)$ \\
\hline Fatigue & $27(87)$ & $8(73)$ & $35(83)$ & $3(60)$ \\
\hline Tiredness & $20(65)$ & $9(82)$ & $29(69)$ & $2(40)$ \\
\hline Less/low energy & $21(68)$ & $7(64)$ & $28(67)$ & $1(20)$ \\
\hline Exhaustion & $7(23)$ & $2(18)$ & $9(21)$ & $0(0)$ \\
\hline Flu-like symptoms & $2(6)$ & $1(9)$ & $3(7)$ & $0(0)$ \\
\hline Lethargy & $2(6)$ & $0(0)$ & $2(5)$ & $0(0)$ \\
\hline Pain & $25(78)$ & $7(64)$ & $32(74)$ & $2(40)$ \\
\hline Sleep issues & $17(55)$ & $4(36)$ & $21(50)$ & $2(40)$ \\
\hline Muscle spasms/twitching & $16(52)$ & $4(36)$ & $20(48)$ & $2(40)$ \\
\hline Spasms & $10(32)$ & $4(36)$ & $14(33)$ & $2(40)$ \\
\hline Twitching & $7(23)$ & $1(9)$ & $8(19)$ & $0(0)$ \\
\hline Both & $2(6)$ & $1(9)$ & $3(7)$ & $0(0)$ \\
\hline Muscle weakness/fatigue/stamina & $13(42)$ & $4(36)$ & $17(40)$ & $1(20)$ \\
\hline Heat intolerance & $11(35)$ & $3(27)$ & $14(33)$ & $0(0)$ \\
\hline Cardiovascular symptoms & $10(32)$ & $4(36)$ & $14(33)$ & $2(40)$ \\
\hline Kidney problems & $9(29)$ & $1(9)$ & $10(24)$ & $0(0)$ \\
\hline General muscle aches/pain & $8(26)$ & $1(9)$ & $9(21)$ & $1(20)$ \\
\hline Joint pain & $7(23)$ & $1(9)$ & $8(19)$ & $0(0)$ \\
\hline General body aches and pains & $6(19)$ & $0(0)$ & $6(14)$ & $0(0)$ \\
\hline Eye problems & $5(16)$ & $0(0)$ & $5(12)$ & $0(0)$ \\
\hline Heaviness in extremities & $4(13)$ & $1(9)$ & $5(12)$ & $0(0)$ \\
\hline Weight gain & $4(13)$ & $1(9)$ & $5(12)$ & $0(0)$ \\
\hline Cold intolerance & $3(10)$ & $1(9)$ & $4(10)$ & $0(0)$ \\
\hline Dizziness/nausea & $3(10)$ & $1(9)$ & $4(10)$ & $0(0)$ \\
\hline Bone pain & $3(10)$ & $0(0)$ & $3(7)$ & $0(0)$ \\
\hline Calcium deposits & $3(10)$ & $0(0)$ & $3(7)$ & $0(0)$ \\
\hline Headaches & $2(6)$ & $1(9)$ & $3(7)$ & $0(0)$ \\
\hline Physical vibration sensation & $2(6)$ & $1(9)$ & $3(7)$ & $0(0)$ \\
\hline Seizures & $2(6)$ & $1(9)$ & $3(7)$ & $3(60)$ \\
\hline Shortness of breath/breathlessness & $2(6)$ & $1(9)$ & $3(7)$ & $1(20)$ \\
\hline
\end{tabular}

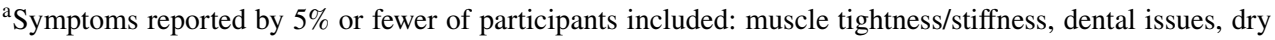
skin, ears ringing, drowsiness, lightheaded, acid reflux, balance issues, bone density loss, bruise easily, droopy cheek, dry mouth, edema, fainting/passing out, groggy, hair loss, joints crack/pop when bending, night sweats, bleeds in nose and elsewhere, pain in fingernails, pain in limbs (not attributed to another symptom in list), peripheral neuropathy, restless legs, reduced sex drive, soft-tissue calcification, voice change/loss, and constipation encompass cognitive impairments, rather than as its own discrete symptom.

Overall, there were no differences in the proportions of participants who reported experiencing the major physical and cognitive symptoms based on comorbidity status. However, there were a few differences in endorsement rates for the minor symptoms. A higher proportion of participants with hypothyroidism reported experiencing kidney problems $(9 / 31,29 \%)$ than those without this comorbidity $(1 / 11,9 \%)$. Conversely, a lower proportion of participants with hypothyroidism $(2 / 31,6 \%)$ reported experiencing impaired decisionmaking ability than those without this comorbidity $(3 / 11$, $27 \%)$. 
Table 3 Cognitive signs and symptoms

\begin{tabular}{|c|c|c|c|c|}
\hline \multirow[t]{2}{*}{ Cognitive signs and symptoms, $n(\%)$} & \multicolumn{2}{|l|}{ Comorbidity status } & \multirow{2}{*}{$\begin{array}{l}\text { Patient total } \\
(n=42)\end{array}$} & \multirow{2}{*}{$\begin{array}{l}\text { Clinician } \\
\text { total }(n=5)\end{array}$} \\
\hline & $\begin{array}{l}\text { Has hypothyroidism } \\
(n=31)\end{array}$ & $\begin{array}{l}\text { Does not have hypothy- } \\
\text { roidism }(n=11)\end{array}$ & & \\
\hline Brain fog & $24(77)$ & $8(73)$ & $32(76)$ & $4(80)$ \\
\hline Memory/forgetfulness & $19(61)$ & $5(45)$ & $24(57)$ & $4(80)$ \\
\hline Short-term memory & $16(52)$ & $4(36)$ & $20(48)$ & $1(20)$ \\
\hline Long-term memory & $5(16)$ & $2(18)$ & $7(17)$ & $0(0)$ \\
\hline Unspecified if long- or short-term memory & $1(3)$ & $0(0)$ & $1(2)$ & $2(40)$ \\
\hline Impaired ability to have a conversation/speech issues & $17(55)$ & $4(36)$ & $21(50)$ & $1(20)$ \\
\hline Trouble finding the correct words to say & $16(52)$ & $4(36)$ & $20(48)$ & $0(0)$ \\
\hline Other impairments to ability to have a conversation & $2(6)$ & $1(9)$ & $3(7)$ & $1(20)$ \\
\hline Lack of concentration/focus & $12(39)$ & $6(55)$ & $18(43)$ & $4(80)$ \\
\hline Can't think right/clearly/fuzzy thinking & $9(29)$ & $4(36)$ & $13(31)$ & $0(0)$ \\
\hline Understanding information & $7(23)$ & $4(36)$ & $11(26)$ & $1(20)$ \\
\hline Feel less sharp/bright & $6(19)$ & $2(18)$ & $8(19)$ & $3(60)$ \\
\hline Get confused easily & $2(6)$ & $3(27)$ & $5(12)$ & $0(0)$ \\
\hline Impaired decision-making ability & $2(6)$ & $0(0)$ & $2(5)$ & $0(0)$ \\
\hline Impulse control & $0(0)$ & $1(9)$ & $1(2)$ & $0(0)$ \\
\hline Impaired ability to problem-solve & $0(0)$ & $1(9)$ & $1(2)$ & $0(0)$ \\
\hline Speaking without a filter & $1(3)$ & $0(0)$ & $1(2)$ & $0(0)$ \\
\hline Impaired writing ability & $0(0)$ & $1(9)$ & $0(0)$ & $0(0)$ \\
\hline
\end{tabular}

\subsubsection{Preliminary Theoretical Model}

Based on the qualitative data analysis results, a preliminary theoretical model of the signs and symptoms of HP was developed (Fig. 1). The model illustrates the hypothesized relationships among the major and minor physical signs and symptoms, proximal impacts, and distal consequences along with potential mediators and modifiers. Potential modifiers and mediators that may mitigate or amplify the impacts experienced by individuals with HP include treatment status, comorbidities, disease severity, age, time with HP, disease etiology, and access to medical care. The model is considered preliminary in nature, as it may require modification based on the psychometric validation of the measure.

\subsection{Item Generation}

Items were generated for the major signs and symptoms while minor signs and symptoms, as well as proximal or distal impacts, were excluded from the measure. Based on the criteria outlined above, 17 signs and symptoms were categorized as major, including muscle cramps, muscle spasms, muscle twitching, muscle weakness, tingling with numbness, tingling without numbness, pain, sensitivity to heat, feeling tired, trouble sleeping, heart problems, low energy, trouble remembering, trouble finding the right words, trouble concentrating, and trouble thinking clearly.
Items were worded as closely as possible to the language used by participants. For each item generated, the qualitative analysis findings were reviewed to confirm that the item reflected a concept considered to be important and bothersome by a majority of the participants who reported experiencing it.

\subsection{Cognitive Debriefing}

A total of 16 adults participated in CD interviews. As with the CE sample, the majority $(n=12,75 \%)$ were female, and had post-surgical HP $(n=11,69 \%)$. The average age was 47 (range 20-63) years. On average, participants had HP for 12 (range 2-50) years. Participants reported an average of three (median two, range zero to nine) comorbidities in addition to their HP, including depression $(n=4,25 \%)$, chronic back pain $(n=4,25 \%)$, and hypothyroidism $(n=3,18 \%)$. The majority reported currently using calcium $(n=14,88 \%)$ and/or vitamin $\mathrm{D}(n=12,75 \%)$ supplements to manage their HP. Half reported currently using magnesium supplements or PTH replacement therapy.

After the first block of interviews, findings were reviewed, and a decision was made as to whether any changes to the HPES-Symptom were necessary. This process continued in blocks of four participants until a determination was made that the readability, clarity, and relevance of all instructions and items, including response options and response scale format, were acceptable based on consensus agreements 


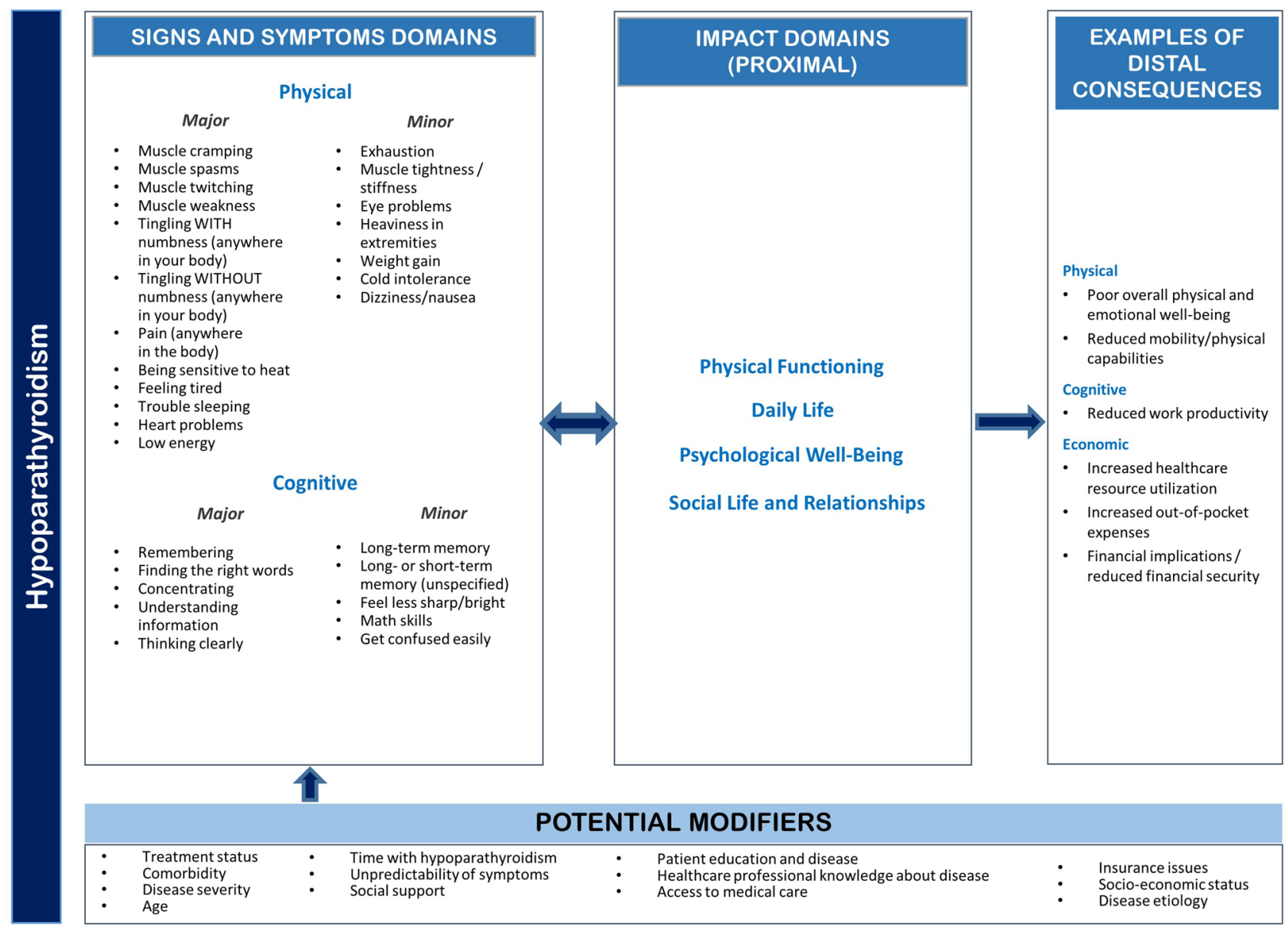

Fig. 1 Preliminary theoretical model of the signs and symptoms of hypoparathyroidism

among respondents in an entire block. A total of four blocks were necessary to refine the HPES-Symptom items in terms of readability and relevance.

The CD resulted in the validation-ready HPES-Symptom tool, which is made up of 17 items using the same stem and response options. For example, respondents are asked, "In the past two weeks, because of your hypoparathyroidism, how often did you experience muscle cramping?" Response options are based on a five-point Likert-type scale, chosen to ensure that meaningful distinctions could be made among responses for analysis while minimizing the cognitive burden for respondents completing the instrument [35]. Response options included "Never", "Occasionally (1-25\% of the time)", "Sometimes (26-50\% of the time)", "Often (51-75\% of the time)", and "Very Often/Always (76-100\% of the time)". A numeric scale was provided for each response option greater than "Never" as a result of feedback from the first block of CD participants, who suggested that this additional quantitative specificity was needed for clarification. The 2-week recall was used to allow for the daily variability of symptoms, which is common for this condition. The appropriateness and ability to answer for a 2-week recall period was examined in the CD interviews. Participants understood and were able to answer in that timeframe. Participants reported taking an average of $4 \mathrm{~min}$ to complete the HPES-Symptom measure and did not consider this to be burdensome.

Table 4 presents representative quotes for each of the 17 HPES-Symptom items.

\section{Discussion}

Study findings suggest that patients with HP experience a substantial burden of illness, both with respect to the range and severity of symptoms associated with the condition. The vast majority of $\mathrm{CE}$ and $\mathrm{CD}$ participants reported experiencing both physical and cognitive signs and symptoms. Very few potentially meaningful differences based on hypothyroidism comorbidity status were identified in the analysis. Based on these findings, this study provides evidence for the 
Table 4 Exemplary quotes for the items in the Hypoparathyroidism Patient Experience Scale-Symptom (HPES-Symptom)

Items Exemplary quotes

Physical signs and symptoms

Muscle cramping

Cramping, usually sharp cramps in the calf that last in duration for about, oh, 10 or $15 \mathrm{~s}$, but are really intense and painful. Sometimes also sharp cramps of the foot or the hand. In more extreme cases, tetany, so the kind of intense cramping with the inability to get the muscles to relax starting in the hands and feet, and then kind of traveling. (206; male, age 28, idiopathic, taking PTH replacement therapy)

I can't tell you how many times I have been to the ER because my hands literally cramp up to- they kind of curl up, and into a big cramp, you can't undo them, you can't use your hands, and it's painful ... I've had it done on my arms, I've had it on my wrists, my legs, because soon as they start doing it, the muscles just cramp completely up. (242; female, age 38, post-surgical, has hypothyroidism, taking PTH replacement therapy)

Muscle spasms

Muscle twitching

Muscle weakness

Tingling with numbness

Tingling without numbness

Pain

Sensitivity to heat

Feeling tired

Trouble sleeping

Heart problems
I have to deal a lot with muscle spasms, and they're not the normal typical muscle spasms, they're like your muscles feel like they're lead bricks and when they tighten, they really feel heavy and hurt. (236; female, age 61 , post-surgical, has hypothyroidism, taking PTH replacement therapy)

Some of them are little spasms and some of them are really big, and the big ones are the painful ones. (202; male, age 59, post-surgical, has hypothyroidism)

[Before taking PTH replacement therapy] I twitched a lot. I would twitch in my eye. I would twitch in my leg. I would twitch in muscles that I didn't even know there was muscles there. (212; female, age 51, post-surgical, has hypothyroidism, taking PTH replacement therapy)

My face starts twitching a little, and my lips get it. (214; female, age 57, post-surgical)

My muscles fatigue very easily now, like even just walking up a flight of stairs. (224; female, age 44, postsurgical, has hypothyroidism)

I've played sports my whole life, so muscle stamina has never been an issue that I've experienced, and then life after my surgery was, okay, I'm going to choose what activity I'm going to do. I may or may not be able to complete it, and even if I do or don't complete it, I will definitely pay for it later. I will pay for it that evening for sure, and in days after, 2 and 3, 4 days, maybe take a week after. (221; female, age 33, post-surgical, has hypothyroidism, taking PTH replacement therapy)

When you wake up in the morning, your hands and fingers are tingling or numb, you have to be careful that you don't just get up and try and get out of the bed because you can fall down because your legs are numb. (243; female, age 60 , post-surgical, has hypothyroidism, taking PTH replacement therapy)

My lips will start feeling numb ... I can tell whenever my calcium starts dropping by the tingling of my lips. (235; female, age 56 , post-surgical, has hypothyroidism)

When you're going to sleep, you just learn to ignore it, but ...they sometimes hurt. I don't know why that should be true, but the tingling will end up causing a whole - all the fingers to kind of make a funny feeling. (237; female, age 69, post-surgical, has hypothyroidism, taking PTH replacement therapy)

The tingling in the hands is usually my first sign. If it's during the day, that's the first sign that I need to take some extra calcium. (233; female, age 58, post-surgical, has hypothyroidism)

Sometimes I can't lift my arms above my head, because the pain in the joints—and I have back pain too. (229; female, age 46, post-surgical, has hypothyroidism)

[Before taking PTH replacement therapy] ... cramps so bad that they would wake me up at, usually around 3 o'clock to 4 o'clock in the morning screaming in pain because of how hard-how much it hurt. (223; female, age 66, post-surgical, taking PTH replacement therapy)

When I am put out in heat, where there's a really high humidity, I have passed out several times. I can't tolerate it when it's really hot. (203; female, age 29 , post-surgical, has hypothyroidism)

We have a hobby of going to flea markets and sometimes we may have to leave early because it's too hot and I cannot take the heat. (238; female, age 69, post-surgical, taking PTH replacement therapy)

I just get really tired, really fatigued. It's not even tired, it's beyond tired. It's like you never really feel like you get your strength back. (213; female, age 71, post-surgical, has hypothyroidism)

I am very tired. Yes, like I hit a wall and I just-I don't know how I can go any further ... just so fatigued all day long. (225; female, age 49, post-surgical, has hypothyroidism, taking PTH replacement therapy)

I wake up frequently in the night because of the tingling or the taser effect, it wakes you up. (234; female, age 73 , post-surgical, has hypothyroidism)

When I'm just sleeping, I'll wake up interruptedly on and off throughout the night. (201, male, age 26, idiopathic, taking PTH)

I always feel like my-always just feels like my heart is really palpitating. (222; male, age 28, post-surgical, has hypothyroidism)

When it's severe I get cardiac symptoms and-you know, chest pain. (217; female, post-surgical, taking PTH replacement therapy) 
Table 4 (continued)

\begin{tabular}{|c|c|}
\hline Items & Exemplary quotes \\
\hline Low energy & $\begin{array}{l}\text { I have hardly any energy. (211; female, age } 39 \text {, post-surgical, has hypothyroidism, taking PTH replacement } \\
\text { therapy) } \\
\text { There are days that I can-I will sit on the couch and either sleep all day or just not have the energy to do much } \\
\text { of anything but get up and use the bathroom. (229; female, age } 62 \text {, post-surgical, has hypothyroidism) }\end{array}$ \\
\hline \multicolumn{2}{|l|}{ Cognitive signs and symptoms } \\
\hline Trouble remembering & $\begin{array}{l}\text { I can't remember somebody's name that they just told me } 2 \mathrm{~s} \text { ago, and I can't remember my last thought that I } \\
\text { was just thinking about, and I'm only } 49 \text { and it's like, I'll say, 'Oh my gosh, I'm hopefully not getting early } \\
\text { Alzheimer's.' I'm like, 'No, no, no, it's just my calcium must be low,' and I have to remind myself. ( } 231 \text {; } \\
\text { female, age } 49 \text {, post-surgical, has hypothyroidism, taking PTH replacement therapy) } \\
\text { I have left stuff on the barbeque grill cooking and not remembered that it's there. I've done that on the stove, } \\
\text { cooking. ( } 241 \text {; female, age 52, has hypothyroidism, post-surgical) }\end{array}$ \\
\hline Finding the right words & $\begin{array}{l}\text { I can't find the word or the phrase that I was looking for, or whatever. Yes. It is pretty bothersome that that hap- } \\
\text { pens. People look at you funny like you lost your mind or something. (202; male, age 59, post-surgical, has } \\
\text { hypothyroidism) } \\
\text { I'd say a couple of times a week, and then it does get more severe and then my husband will actually notice it, } \\
\text { where I'm searching for words or I will mix my words up. (232; female, age 59, post-surgical, has hypothy- } \\
\text { roidism, taking PTH replacement therapy) }\end{array}$ \\
\hline Concentrating & $\begin{array}{l}\text { My focus is way reduced, that I'm not able to focus on one task for a long time. ( } 240 \text {; female, age 44, post- } \\
\text { surgical, has hypothyroidism) } \\
\text { [Before PTH replacement therapy] Trouble concentrating ... I would notice that I would have trouble focusing } \\
\text { on tasks at hand a lot of times ... A lot of times I would just kind of take a quick break and regroup. ( } 219 \text {; } \\
\text { female, age 56, post-surgical, taking PTH replacement therapy) }\end{array}$ \\
\hline Understanding information & $\begin{array}{l}\text { It makes it really difficult to think, to process and hold information. (205; male, age } 35 \text {, idiopathic, taking PTH } \\
\text { replacement therapy) } \\
\text { I've always been really bright academically. Schoolwork's always come easy to me. I mean, I just finished my } \\
\text { last semester and I still got a } 4.0 \text {, but I had to work so much harder to try and retain things, read things ... I } \\
\text { just feel like my brain, how it processes things has changed so much. (215; female, age } 31 \text {, post-surgical) }\end{array}$ \\
\hline Thinking clearly & $\begin{array}{l}\text { Inability to think clearly ... that kind of odd 'I can't really make sense of the world' kind of thing. (216; female, } \\
\text { age } 61 \text {, post-surgical, has hypothyroidism, taking PTH replacement therapy) } \\
\text { I experience it more like having trouble thinking ... like my entire brain is mushy and soft and it's just hard to } \\
\text { really think through any ideas. ( } 218 \text {; female, age } 61 \text {, post-surgical, has hypothyroidism) }\end{array}$ \\
\hline
\end{tabular}

PTH parathyroid hormone

content validity of the signs and symptoms captured in the HPES-Symptom.

Prior research suggests that the signs and symptoms associated with HP may also impact patient HRQOL [19-23, 36]. In this study, impacts associated with HP symptoms were reported across four HRQOL domains: physical functioning, daily life, psychological well-being, and social life and relationships. In addition to developing the HPESSymptom measure, the findings on impacts were used to develop a separate disease-specific, patient-reported impact measure on how HP affects daily functioning and well-being (to be reported separately). The symptoms identified in this study are similar to those included in a recently developed symptom diary for this condition, lending support to the validity of our findings [37].

Having access to a brief disease-specific measure of the signs and symptoms of HP experienced by patients has the potential to enhance their clinical care. A validated diseasespecific composite measure of symptoms and their effects on HRQOL would be useful and help standardize the language used to describe the severity of the clinical syndrome in individual patients. Although HP is seldom immediately life threatening, it imposes a substantial HRQOL burden on many patients [1, 17, 21-23]. However, some patients with HP are minimally symptomatic or completely asymptomatic. At present, there is no easily applied, convenient method to classify such patients for ease of communication and to help place into context the potential risks and benefits of various therapies for HP. The goal is for the HPES-Symptom to be a brief useful tool for assessing symptoms of HP from the patient perspective, and to use the HPES-Symptom in future studies that evaluate disease burden or treatment efficacy relating to symptom improvement.

As with all research, this study has limitations. While efforts were made to recruit a diverse sample of study participants, the majority were female and had post-surgical $\mathrm{HP}$, which is similar to the sample compositions in other studies of patients with HP [17, 20, 38]. In addition, most participants were White/Caucasian, and it was a US-based population. However, the clinical experts from Denmark reported observing similar signs and symptoms among their patients, and studies describing patients with HP in Canada, 
India, and multiple European countries provide evidence that the measure may also be appropriate for assessments in other populations $[17,19,36,39,40]$. Cultural and linguistic validation of the measure would be required for use in non-US populations. This study was also limited to an adult population. Additional CE research would be required to explore whether signs and symptoms differ for children and adolescents.

Given the sample sizes within each CE subgroup and the differences in the numbers of participants within the hypothyroidism vs. non-hypothyroidism subgroups ( $n=30$ vs. $n=11$ ), study findings based on subgroups should be interpreted with caution. There were also variations within each subgroup that may affect the burden of illness, such as other comorbidities, duration of time with HP, and a high proportion of participants without hypothyroidism who were taking PTH replacement therapy $(8 / 11,73 \%)$. A quantitative survey study would be appropriate to further explore variations among subgroups based on treatment status, comorbidities, and other potential modifiers such as sex, age, disease etiology, and length of time with the condition.

\section{Conclusions}

The study findings provide evidence of content validity for the validation-ready HPES-Symptom measure, which includes 17 items across two domains of signs and symptoms: Physical and Cognitive. The identification of the major patient-reported signs and symptoms of HP can provide the basis for a validated PRO measure to enable clinicians and researchers to assess the impact of treatments for this condition, including examining the differences between treatments, and assessment of the treatment risk/ benefit ratio. Additional research is needed to validate the HPES-Symptom measure in patients with HP to determine whether it is a reliable measure. Factor analysis will be performed in the validation study to confirm the measurement properties and factor structure of the measure. While the preliminary theoretical model may be used to inform future research using the HPES-Symptom measure, modifications to the model may be required.

Author contributions $\mathrm{MB}$ contributed to the research design, analysis, measure development, and manuscript preparation and is the overall guarantor; LTW contributed to the research design, analysis, measure development, and manuscript preparation; AS and DK contributed to the research design and manuscript preparation.

\section{Compliance with Ethical Standards}

Funding This study was funded by Ascendis Pharma.
Conflict of interest Meryl Brod and Laura Tesler Waldman are consultants to the pharmaceutical industry, including Ascendis Pharma. Alden Smith is an employee of Ascendis Pharma and received stock options as an employee of Ascendis Pharma. David Karpf is an employee of Ascendis Pharma and received stock/stock options as an employee of Ascendis Pharma.

Ethics approval All procedures performed in studies involving human participants were in accordance with the ethical standards of the institutional and/or national research committee (Copernicus Group Institutional Review Board, tracking \#420180290) and with the 1964 Helsinki Declaration and its later amendments or comparable ethical standards.

Consent to participate Informed consent was obtained from all individual participants included in the study.

Data availability The data for the research presented in the publication may be available from the corresponding author, on reasonable request.

Open Access This article is distributed under the terms of the Creative Commons Attribution-NonCommercial 4.0 International License (http://creativecommons.org/licenses/by-nc/4.0/), which permits any noncommercial use, distribution, and reproduction in any medium, provided you give appropriate credit to the original author(s) and the source, provide a link to the Creative Commons license, and indicate if changes were made.

\section{References}

1. Mannstadt M, Bilezikian JP, Thakker RV, Hannan FM, Clarke BL, Rejnmark L, et al. Hypoparathyroidism. Nat Rev Dis Primers. 2017;3:17080. https://doi.org/10.1038/nrdp.2017.80.

2. Bilezikian JP, Khan A, Potts JT Jr, Brandi ML, Clarke BL, Shoback D, et al. Hypoparathyroidism in the adult: epidemiology, diagnosis, pathophysiology, target-organ involvement, treatment, and challenges for future research. J Bone Miner Res. 2011;26(10):2317-37. https://doi.org/10.1002/jbmr.483.

3. Cusano NE, Rubin MR, Bilezikian JP. PTH(1-84) replacement therapy for the treatment of hypoparathyroidism. Expert Rev Endocrinol Metab. 2015;10(1):5-13. https://doi. org/10.1586/17446651.2015.971755.

4. Parfitt AM. The actions of parathyroid hormone on bone: relation to bone remodeling and turnover, calcium homeostasis, and metabolic bone diseases. II. PTH and bone cells: bone turnover and plasma calcium regulation. Metabolism. 1976;25(8):909-55.

5. Kroll MH. Parathyroid hormone temporal effects on bone formation and resorption. Bull Math Biol. 2000;62(1):163-88. https:// doi.org/10.1006/bulm.1999.0146.

6. Dempster DW, Cosman F, Kurland ES, Zhou H, Nieves J, Woelfert $\mathrm{L}$, et al. Effects of daily treatment with parathyroid hormone on bone microarchitecture and turnover in patients with osteoporosis: a paired biopsy study. J Bone Miner Res. 2001;16(10):1846-53. https://doi.org/10.1359/jbmr.2001.16.10.1846.

7. National Organization for Rare Disorders. Hypoparathyroidism. Resource document. 2017. https://rarediseases.org/rare-diseases/ hypoparathyroidism/. Accessed 10 Oct 2018.

8. Clarke BL, Leibson C, Emerson J, Ransom JE, Lagast H. Comorbid-medical conditions associated with prevalent hypoparathyroidism: a population-based study [abstract SA0170]. J Bone Miner Res. 2011;26(S1):S182.

9. Clarke BL, Brown EM, Collins MT, Juppner H, Lakatos P, Levine MA, et al. Epidemiology and diagnosis of hypoparathyroidism. 
J Clin Endocrinol Metab. 2016;101(6):2284-99. https://doi. org/10.1210/jc.2015-3908.

10. Astor MC, Løvås K, Debowska A, Eriksen EF, Evang JA, Fossum C, et al. Epidemiology and health-related quality of life in hypoparathyroidism in Norway. J Clin Endocrinol Metab. 2016;101(8):3045-53.

11. Kisand K, Peterson P. Autoimmune polyendocrinopathy candidiasis ectodermal dystrophy. J Clin Immunol. 2015;35(5):463-78. https://doi.org/10.1007/s10875-015-0176-y.

12. Nair KS, Holdaway IM, Evans MC, Cameron AD. Influence of magnesium on the secretion and action of parathyroid hormone. J Endocrinol Investig. 1979;2(3):267-70. https://doi.org/10.1007/ bf03350414.

13. Saggese G, Federico G, Bertelloni S, Baroncelli GI, Calisti L. Hypomagnesemia and the parathyroid hormone-vitamin D endocrine system in children with insulin-dependent diabetes mellitus: effects of magnesium administration. J Pediatr. 1991;118(2):220-5.

14. Shoback D. Clinical practice: hypoparathyroidism. N Engl J Med. 2008;359(4):391-403. https://doi.org/10.1056/NEJMcp0803050.

15. Shire-NPS Pharmaceuticals. Natpara ${ }^{\circledR}$ prescribing guide. 2018. https://www.shirecontent.com/PI/PDFs/Natpara_USA_ENG.pdf. Accessed 16 Oct 2018.

16. Cusano NE, Rubin MR, Irani D, Sliney J Jr, Bilezikian JP. Use of parathyroid hormone in hypoparathyroidism. J Endocrinol Investig. 2013;36(11):1121-7. https://doi.org/10.1007/bf03346763.

17. Sikjaer T, Rolighed L, Hess A, Fuglsang-Frederiksen A, Mosekilde L, Rejnmark L. Effects of PTH(1-84) therapy on muscle function and quality of life in hypoparathyroidism: results from a randomized controlled trial. Osteoporos Int. 2014;25(6):171726. https://doi.org/10.1007/s00198-014-2677-6.

18. Sikjaer T, Moser E, Rolighed L, Underbjerg L, Bislev LS, Mosekilde L, et al. Concurrent hypoparathyroidism is associated with impaired physical function and quality of life in hypothyroidism. J Bone Miner Res. 2016;31(7):1440-8. https://doi. org/10.1002/jbmr.2812.

19. Arlt W, Fremerey C, Callies F, Reincke M, Schneider P, Timmermann W, et al. Well-being, mood and calcium homeostasis in patients with hypoparathyroidism receiving standard treatment with calcium and vitamin D. Eur J Endocrinol. 2002;146(2):215-22.

20. Hadker N, Egan J, Sanders J, Lagast H, Clarke BL. Understanding the burden of illness associated with hypoparathyroidism reported among patients in the PARADOX study. Endocr Pract. 2014;20(7):671-9. https://doi.org/10.4158/ep13328.or.

21. Buttner M, Musholt TJ, Singer S. Quality of life in patients with hypoparathyroidism receiving standard treatment: a systematic review. Endocrine. 2017;58(1):14-20. https://doi.org/10.1007/ s12020-017-1377-3.

22. Rejnmark L. Quality of life in hypoparathyroidism. Endocrine. 2018;59(2):237-8. https://doi.org/10.1007/s12020-017-1479-y.

23. Vokes T. Quality of life in hypoparathyroidism. Bone. 2019;120:542-7. https://doi.org/10.1016/j.bone.2018.09.017.

24. Winer KK. Advances in the treatment of hypoparathyroidism with PTH 1-34. Bone. 2019;120:535-41. https://doi. org/10.1016/j.bone.2018.09.018.

25. US Department of Health and Human Services. Guidance for industry: patient-reported outcome measures: use in medical product development to support labeling claims. 2009. https:// www.fda.gov/media/77832/download. Accessed 7 June 2019.

26. Brod M, Tesler LE, Christensen TL. Qualitative research and content validity: developing best practices based on science and experience. Qual Life Res. 2009;18(9):1263-78. https:// doi.org/10.1007/s11136-009-9540-9.

27. Lasch KE, Marquis P, Vigneux M, Abetz L, Arnould B, Bayliss $\mathrm{M}$, et al. PRO development: rigorous qualitative research as the crucial foundation. Qual Life Res. 2010;19(8):1087-96. https:// doi.org/10.1007/s11136-010-9677-6.

28. Patrick DL, Burke LB, Gwaltney CJ, Leidy NK, Martin ML, Molsen E, et al. Content validity: establishing and reporting the evidence in newly developed patient-reported outcomes (PRO) instruments for medical product evaluation. ISPOR PRO good research practices task force report. Part 2. Assessing respondent understanding. Value Health. 2011;14(8):978-88. https:// doi.org/10.1016/j.jval.2011.06.013.

29. Patrick DL, Burke LB, Gwaltney CJ, Leidy NK, Martin ML, Molsen E, et al. Content validity: establishing and reporting the evidence in newly developed patient-reported outcomes (PRO) instruments for medical product evaluation. ISPOR PRO good research practices task force report. Part 1. Eliciting concepts for a new PRO instrument. Value Health. 2011;14(8):967-77. https://doi.org/10.1016/j.jval.2011.06.014.

30. Sturges JE, Hanrahan KJ. Comparing telephone and faceto-face qualitative interviewing: a research note. Qual Res. 2004;4(1):107-18.

31. Holt A. Using the telephone for narrative interviewing: a research note. Qual Res. 2010;10(1):113-21.

32. Drabble L, Trocki KF, Salcedo B, Walker PC, Korcha RA. Conducting qualitative interviews by telephone: lessons learned from a study of alcohol use among sexual minority and heterosexual women. Qual Soc Work. 2016;15(1):118-33.

33. Corbin J, Strauss A. Basics of qualitative research. 3rd ed. Techniques and procedures for developing grounded theory. Thousand Oaks: Sage Publications, Inc.; 2008. https://doi. org/10.4135/9781452230153.

34. Cutcliffe JR. Methodological issues in grounded theory. J Adv Nurs. 2000;31(6):1476-84.

35. Dillman DA, Smyth JD, Christian LM. Internet, phone, mail, and mixed-mode surveys: the tailored design method. 4th ed. Hoboken: Wiley; 2014.

36. Astor MC, Lovas K, Debowska A, Eriksen EF, Evang JA, Fossum C, et al. Epidemiology and health-related quality of life in hypoparathyroidism in Norway. J Clin Endocrinol Metab. 2016;101(8):3045-53. https://doi.org/10.1210/jc.2016-1477.

37. Coles T, Chen K, Nelson L, Harris N, Vera-Llonch M, Krasner A, et al. Psychometric evaluation of the hypoparathyroidism symptom diary. Patient Relat Outcome Meas. 2019;29(10):25-36.

38. Rubin MR, Cusano NE, Fan WW, Delgado Y, Zhang C, Costa AG, et al. Therapy of hypoparathyroidism with PTH(1-84): a prospective six year investigation of efficacy and safety. J Clin Endocrinol Metab. 2016;101(7):2742-50. https://doi.org/10.1210/ jc.2015-4135.

39. Aggarwal S, Kailash S, Sagar R, Tripathi M, Sreenivas V, Sharma $R$, et al. Neuropsychological dysfunction in idiopathic hypoparathyroidism and its relationship with intracranial calcification and serum total calcium. Eur J Endocrinol. 2013;168(6):895-903. https://doi.org/10.1530/eje-12-0946.

40. Chen K, Krasner A, Li N, Xiang C, Sourotzidis A, Xie J. Clinical and economic burden associated with chronic hypoparathyroidism: a retrospective chart review in the United States, Canada, United Kingdom, France, Germany, Italy, and Spain (abstract). Endocr Rev. 2017;38(Suppl 1):i. 